\section{Conflitos sociais e a formação da Amazônia}

\author{
Por Breno Rodrigo de Oliveira Alencar \\ Museu Paraense Emílio Goeldi \\ (brodrigo@museu-goeldi.br)
}

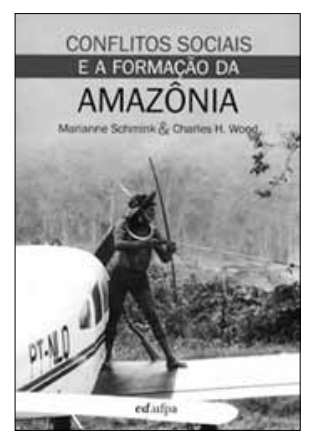

\begin{abstract}
SCHMINK, Marianne; WOOD, Charles $\mathrm{H}$.

Conflitos sociais e a formação da Amazônia.

Tradução de Noemi Miyasaka Porro e Raimundo Moura. Belém: EDUFPA, 2012. 496 p. il. ISBN 978-85247-0513-7
\end{abstract}

Ao norte da vila, onde os dois rios se juntam, as águas claras do Xingu na margem oeste correm ao lado das águas barrentas do Fresco nas margens a leste. A nítida divisão entre eles, que só se esvanece muitos quilômetros abaixo, servia como um símbolo vivo e dinâmico dos confrontos entre a vida tradicional e a vida contemporânea na Amazônia (p. 373).

A obra "Conflitos sociais e a formação da Amazônia", de Marianne Schmink e Charles Wood, inevitavelmente se tornará um clássico das ciências sociais. Trata-se de uma valiosa contribuição à crescente literatura sobre a Amazônia. Publicado pela primeira vez na Universidade de Columbia, Estados Unidos, em 1992, o livro chegou ao público brasileiro pelas mãos dos tradutores Noemi Miyasaka Porro e Raimundo Moura, com vinte anos de atraso, mas em um contexto muito oportuno, pois se inseriu no ambiente dos debates que movimentaram a Conferência das Nações Unidas sobre Desenvolvimento Sustentável (Rio +20), ocorrida no Rio de Janeiro em junho de 2012.

Talvez preocupado com o hiato temporal de sua tradução, o projeto editorial empreendido pela Editora da Universidade Federal do Pará reservou para o trabalho os melhores e mais modernos recursos de confecção, impressão e acabamento. Tanto para o leitor interessado no assunto quanto para um bibliófilo esses detalhes saltam aos olhos, pois entusiasmam e tornam a leitura prazerosa. Por isso, o livro deve ser avaliado desde a ilustração utilizada na capa, de autoria de Eduardo Kalif, onde o imaginário suscitado por um indígena anônimo armado com arco e flecha em posição de ataque sobre a asa direita de um avião monomotor permite, sem apologismo, compreender a natureza da pesquisa: apresentar ao leitor os efeitos colaterais da invasão do 'progresso' e suas reapropriações e readaptações pelo homem local.

Sendo resultado de uma década e meia de pesquisas realizadas no sul do Pará, a publicação reacende o debate sobre as transformações vividas pelos habitantes da região mais violenta da Amazônia no período entre a ascensão da ditadura militar, na década de 1960, e a transição para a Nova República, no fim da década de 1980. Portanto, o livro, como já afirmara Donald Sayer, não é uma coletânea de trabalhos produzidos ao longo desta trajetória, como se fosse um álbum de lembranças incompletas e repetitivas, mas uma interpretação integrada e contemporânea da realidade amazônica. Neste sentido é que os autores frisam o jogo das forças sociais e políticas, ou seja, a historicidade, documentando, sistematicamente, as lutas entre grupos sociais - não definidos como 'classes' sociais -, cujos resultados não se revelaram pré-determinados.

Como o título do livro sugere, os conflitos entre os diferentes grupos de atores é o tema dominante. $O$ contexto da pesquisa que lhe deu origem foi marcado pela morte de milhares de pessoas envolvidas na luta pelo acesso à riqueza mineral, agrária ou madeireira, disputada entre fazendeiros, posseiros, empresas de colonização privada, garimpeiros, mineradoras e serrarias. Unidades militares, guerrilheiros, políticos, líderes religiosos e sindicais, tribos indígenas, ribeirinhos, moradores de vilas, remanescentes das elites extrativistas e burocratas de órgãos federais e estaduais também contribuíram para o conflito.

O livro tece histórias menores e maiores, em uma integração bem sucedida entre caso e contexto. No prefácio à edição brasileira, os autores aproximam esse 
método àquilo que Marx (1985), em seu "18 Brumário...", nos remete ao passado na intenção de compreender as cicatrizes do presente, deixando claro para o leitor que a história da Amazônia é o legado das ações de suas sucessivas gerações. Portanto, a dinâmica e a complexidade da região estariam envolvidos numa seara de conflitos entre o tradicional e o moderno, entre o local e o global, entre o homem e a natureza, que leva os autores a seguirem os rastros de invenção da região, combinando história, sociologia e antropologia para descrever este processo.

Entre as principais virtudes do trabalho empreendido por Schmink e Wood estão o trabalho com as mais diferentes fontes, entre elas a oficial, presente nos gabinetes e relatórios das mais diferentes instituições do governo, e o uso das mais de mil entrevistas, das quais 400 fazem parte do levantamento realizado em São Félix do Xingu. Os autores também são admiravelmente imparciais em apresentar os pontos de vista dos diferentes grupos. Ao invés de retratar índios e agricultores sem terra como sujeitos passivos que sofrem nas mãos de todos os outros, o livro tem o cuidado de denunciar casos de violência e exploração por todos, demonstrando que não há vilões ou mocinhos, mas personagens de uma história em construção, cujos interesses são o motor das transformações que moldam a região.

Iniciada em 1976, a pesquisa prosseguiu em 1978 e em mais seis outras visitas realizadas entre 1980 e 1989. O local escolhido para o estudo é o que hoje se conhece como sul do Pará, mais precisamente a área entre os rios Araguaia e Xingu. A região também já foi conhecida como 'fronteira agrícola da Amazônia', 'terra do meio' ou 'bico do papagaio'. Por 'fronteira', os autores entendem uma região liminar no contexto da ocupação por agentes econômicos capitalistas. Entre as cidades citadas no trabalho estão Tucumã, Ourilândia do Norte, Água Azul, Xinguara, Rio Maria, Redenção, Conceição do Araguaia, Marabá, Itupiranga e São Félix do Xingu, esta última considerada o centro do qual se irradiam as interpretações sobre a região. Assim, utilizando-se de um levantamento bibliográfico vasto, da descrição do contexto social, político e econômico ao longo dos sucessivos ciclos de ocupação e da familiaridade com os problemas da região, os autores seguem o rastro dos elementos que compõem o cenário do surgimento de conflitos e violentas disputas pelo acesso à terra e suas riquezas pelos diferentes agentes sociais.

Diversos interesses estavam em jogo, pois o contexto geopolítico do sul do Pará era determinado por posicionamentos ideológicos que alimentavam uma perigosa discussão sobre ausências, carências, ineficiência e necessidade de intervenção do Estado, que terminou por coincidir com a criação do Programa de Integração Nacional, sustentado pelo que se convencionou chamar de 'milagre econômico brasileiro'. Esta política teve como base a mentalidade predominante do Eldorado, envolvia a exploração econômica setorial e a quase ilimitada distribuição territorial da periferia da Amazônia (Kohlhepp, 2002). Tratava-se de um cenário onde as estratégias de planejamento eram concentradas no conceito de 'pólo de crescimento', previsto no Segundo Plano de Desenvolvimento Nacional (1975-1979) e baseado em pontos focais setoriais separados, como, por exemplo, extração de recursos minerais ou áreas de criação de gado com possível processo industrial. A pesquisa dá conta de uma invasão de investidores de capital nacional e internacional, atraídos por reduções consideráveis de taxas tributárias.

Neste sentido, era objetivo da pesquisa rastrear a evolução dos eventos de fronteira, verificando o tipo e a intensidade dos conflitos sociais surgidos com a criação do Programa Polamazônia no contexto das políticas desenvolvimentistas. A metodologia utilizada incluiu o levantamento de dados; a aplicação de questionários em residências selecionadas aleatoriamente na cidade de São Félix do Xingu; entrevistas com burocratas nos órgãos governamentais das cidades do sudeste do Pará e em Brasília; e o contato por meio de informantes-chave, escolhidos por suas posições estratégicas nos diferentes

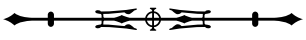


órgãos administrativos e nas atividades econômicas nos locais do estudo e nas capitais estadual e federal. Essa metodologia transformou a pesquisa, nas palavras dos autores, em uma verdadeira história de detetive, uma vez que a natureza dos relatos colhidos sugeria uma infinidade de atores envolvidos na investigação.

Os sucessivos capítulos, repletos de fatos, nomes, datas e lugares, enorme riqueza empírica em razão de sofisticada organização e interpretação pouco ostensiva, superam uma abordagem menos descritiva e elucidam, em retrospectiva, a origem dos conflitos. Assim, logo após a introdução, a primeira seção oferece um relato cronológico da história de ocupação e das políticas de desenvolvimento implementadas na Amazônia. $\bigcirc$ relato começa com o contato europeu, com mais detalhes dedicados às rápidas mudanças que ocorreram desde o começo do trabalho de campo em 1976. São elementos centrais neste contexto o processo de ocupação associado aos fatores que condicionaram a migração para a Amazônia; o populismo militar, que os autores consideram ser o emprego de recursos e pessoal em campanhas de ações cívicas na década de 1970 (Ferreira, 2001; Weffort, 1989); e a mobilização e organização dos grupos sociais em resposta à incompetência do Estado na resolução dos conflitos.

A segunda parte do livro trata das repercussões dos contínuos ciclos econômicos da Amazônia na região sul do Pará e da reviravolta provocada pela construção da Transamazônica, que simbolizou o deslocamento do eixo de transporte no sul do Pará, transferindo-o dos rios para as estradas. Narra também o surgimento da Rodovia PA-279 e o desenvolvimento das cidades, das áreas de assentamento e de mineração que surgiram ao longo da rodovia.

A última parte do livro apresenta os resultados de uma série de questionários formais aplicados em intervalos ao longo de um período de seis anos (1978-1984), em São Félix do Xingu, cidade ribeirinha tradicional, rapidamente transformada após a chegada da estrada e a intensa migração de colonos. Ao mesmo tempo, registra as transformações provocadas por essa migração, apresentando os indicadores sociodemográficos e os grupos sociais que se beneficiaram durante este processo.

Em linhas gerais, o livro de Schmink e Wood não só se constitui em referência obrigatória para pesquisadores da Amazônia, como também oferece um estudo de caso importante para quem quiser pesquisar questões mais amplas, como capitalismo na periferia, heterogeneidade estrutural, setor informal, agricultura e fronteira, mineração periférica e, ainda, o papel da dinâmica populacional nesses processos. $\mathrm{Na}$ análise deste leque de assuntos, cabe levar em conta o cenário das transformações enfrentadas pelo Estado brasileiro entre a ditadura e a Nova República, entre elas o enfraquecimento do controle federal sobre o processo de colonização fundiária, a mudança no equilíbrio de forças em favor de grupos políticos progressistas no sul do Pará, ligados à Igreja Católica e a partidos políticos de esquerda, e o fracasso da colonização agrícola, especialmente ao longo da Transamazônica. Destaca-se também o que pode ser considerado o achado principal do livro, isto é, o aprendizado da organização coletiva de seringueiros, garimpeiros, pequenos agricultores, indígenas e ribeirinhos, num contexto que privilegiou o grande capital. Esses grupos se mobilizaram e aprenderam a proteger seus interesses mais efetivamente contra as ameaças de fazendeiros, companhias de mineração, especuladores de terras e burocratas.

Os eventos no sul do Pará são suficientemente dramáticos para afetar mudanças ambientais globais, como emissões de gases de efeito estufa, perda da biodiversidade e alteração no ciclo hidrológico regional. Quando eventos paralelos em outros lugares da Amazônia são considerados, estas alterações ganham importância ainda maior. Uma compreensão exata do contexto social do desmatamento é essencial para quem quiser sugerir alternativas ao problema, especialmente se estas não implicarem mais sofrimento da população. Este livro é uma contribuição vital para promover tal entendimento.

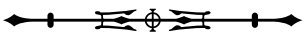




\section{REFERÊNCIAS}

FERREIRA, J. (Org.). O populismo e sua história: debate e crítica. Rio de Janeiro: Civilização Brasileira, 2001.

KOHLHEPP, G. Conflitos de interesse no ordenamento territorial da Amazônia brasileira. Estudos Avançados, v. 16, n. 45, p. 37-61, 2002.
MARX, K O Dezoito Brumário de Luís Bonaparte. 3. ed. São Paulo: Abril Cultural, 1985.

WEFFORT, F. O populismo na política brasileira. 4. ed. Rio de Janeiro: Paz e Terra, 1989. 